\title{
What ever is happening to urban planning and urban design? Musings on the current gap between theory and practice
}

\author{
Pier Carlo Palermo
}

\begin{abstract}
Over the last decades, the gap between disciplinary dreams and real outcomes has been growing in the field of urban planning and urban design. Great difficulties are evident in problematic contexts as the Italian case, but in other countries as well, where planning and design traditions have certainly been reliable and influential (e.g. the Netherlands and the UK). However, there is an astonishing lack of critical reflections within the disciplinary field. The aim of this paper is to focus on a set of critical issues, and to suggest new directions in the current practice. This means to deal with three challenges of great importance: how to overcome the traditional divide between planning and design theory and practice; to select suitable and mutually consistent paradigms within each disciplinary field; and to outline a place-based approach to actual problems in regulation, visioning and urban designing.
\end{abstract}

\section{Foreword}

In a recent work that constitutes an interesting exception in a context which is on the whole lacking in terms of thought-provoking contributions, Bent Fylvbjerg notes that the literature in the discipline pays very little attention to "uncomfortable knowledge" (Flyvbjerg 2013). In a variety of contexts, a large number of experiences demonstrate that planning mistakes tend to proliferate, and the difference between hopes, plans and effective outcomes is ever wider. However, these empirical observations do not appear to give rise to a real desire for critical thinking and, where necessary, changes to the stances and behaviour adopted within the discipline. To the contrary, the discourse strategies most common used tend to deny that the situation is worrying. Difficulties are minimised, or are glossed over with rhetorical distractions. The author notes that this behaviour may lead to ethical problems for the professional category. In fact, the planner risks being seen to shirk several clear public and social responsibilities. Why is this tendency so widespread? The main reason, according to Fylvbjerg, appears to be the desire to present

Correspondence: piercarlo.palermo@polimi.it

Politecnico di Milano, Department of Architecture and Planning, Via Bonardi 3, Milano, Italy

\section{Springer}

(c) 2014 Palermo; licensee Springer. This is an Open Access article distributed under the terms of the Creative Commons Attribution License (http://creativecommons.org/licenses/by/4.0), which permits unrestricted use, distribution, and reproduction in any medium, provided the original work is properly credited. the public with a positive image of the discipline. Excessive doubt and criticism could compromise the trust the public places in urban planning, and hence the potential role of the professionals involved. Moreover, Fylvbjerg asks: how can knowledge and its practical application progress if space for true critical thinking is not provided for?

Perhaps this is one of the factors that may contribute to explain the decline of urban planning in this phase. However, even in the field of urban design it is not easy to maintain that critical thinking is currently thriving and widely supported. The paradox remarked upon by Rem Koolhaas (Koolhaas, 1995) almost twenty years ago is as relevant as it ever was. Real processes express a growing demand for good urbanism. From Koolhaas's viewpoint, this notion cannot be divorced from the quality and efficacy of urban design. However, on the whole the results appear to be less than satisfactory. The capacity to direct and control spatial transformation appears weak not only from the regulatory point of view, but also from that of the effective capacity in terms of visioning and urban designing. In general, doubt is cast upon the social role and influential capacity of the disciplines of spatial organisation and transformation. Is there nothing left to do but adopt some form of "lite urbanism", an ad hoc, adaptive version, which is lacking in true ambition for innovation 
(Koolhaas 1995)? It is difficult to find an answer by way of theoretical reflection, which remains abstract and often elusive.

Indeed, urban design continues to oscillate between tendencies that are blatantly eclectic and those that are excessively conformist (Krieger and Saunders 2009; Banerjee and Luokaitou-Sideris 2011). On one hand, the discipline appears to be willing to accept the growing polysemy of possible references. These may vary from Premodern nostalgia (as in Sitte 1889, and also Unwin 1909), up to the most ephemeral and arbitrary expressions of Postmodern culture (Ponzini and Nastasi 2011). Between these extremes, there is no shortage of stillborn attempts to relaunch the innovative and emancipatory objectives of the Modern project. As is well-known, the most significant tendencies in the United States emerged from Harvard, and later from the University of Pennsylvania between 1950 and 1960 (Mumford 2009, Birch 2011). Contemporary strands, with some similarities, may be found in Europe, in the themes of the townscape (Cullen 1961), urban morphological studies (Quaroni 1967, Aymonino 1975, Huet 1984, Panerai et al. 1999) and the "urban project" (in particular in France and Spain from the 1980's onwards: Portas 1998). On the whole, with regard to this eclectic variety, the culture of the discipline does not seem to express a single coherent position, or even clear alternative stances, for that matter. Which evaluations and strands should be privileged? Or should we conclude that "everything goes", following a rationale of pure convenience?

In truth, some academic and professional groups propose a peculiar representation of the issue, identifying a few, well-defined models that practitioners should conform to. This is the case of New Urbanism (Duany and Plater-Zyberg 1991; Katz 1994; Dutton 2000), which in the last twenty years has attempted to offer a new manifesto of ideas to the theories and practices of urban transformation. In reality, the crucial field of experience has always been considerably limited, more often than not to invention in suburban areas whose inhabitants are relatively homogeneous in social terms, being of the middle-upper classes. The idea of the urban condition is closely connected with environments and life experiences that are rather traditional, even though this is a period of great change (Soja 2000). Hence, the capacity to face the real problems of the informal city, urban sprawl and the megacity, in other words, those emerging forms of settlement that today raise the greatest number of problems, has been backgrounded. Worthy of note is the more recent activism of some groups that have sprung up around the themes of placemaking (such as PPS, Project for Public Spaces, and RUDI, Resource for Urban Design Information). These express orientations bearing considerable similarity to the ideology of New
Urbanism. "Place-making has the potential to be one of the most transformative ideas of this century" (Project for Public Spaces PPS 2008). In reality, these are mostly forms of intervention that are local in terms of destination and interest, and often regard solely the design of public spaces, in relatively homogeneous contexts. One of the particular characteristics should be the emphasis on local knowledge, that is, recognising the possibility of involving the inhabitants themselves as expert informants, so as to decide upon the destiny of areas undergoing transformation, and even some technical solutions, in a participatory manner (Madden 2011). Unfortunately, this hypothesis appears simplistic when considering the critical conditions of contemporary urban areas. Some limitations may be seen also in another movement that has emerged in recent decades, that of landscape urbanism (Mostafavi and Najle 2003; Waldheim 2006).

There is little doubt that some current forms of complex settlement, such as the megacity described by Graham Shane, include a heterogeneous variety of components, and in particular, strips of territory with associated environmental and landscape characteristics (Shane 2011). The issue of "stitching and binding" heterogeneous materials becomes a crucial need. Yet the landscape urbanism approach risks appearing simply too specialised with regards to the necessary integration with other emerging issues of analysis and planning. The risk is that of yet again deeming the notion of landscape to be that of settlement contexts with low levels of anthropisation, rather than envisaging a more radical notion of urban landscape, as a tapestry of shapes, meanings and experiences of urban life (Maciocco 2008). This is the notion that any paradigm of urban design, urbanism or urban planning must come to terms with today.

At the same time, however, the culture of urban planning continues to display certain patterns of involution. The ambitions declared on its foundation at the start of modernity, often realised in unsustainable ways, even in the second half of the 1900's (Boyer 1983) were followed by appeasing visions lacking a solid basis and real effectiveness, such as the strand of "collaborative planning" which saw its heyday in the 1990's (Healey 1997), as well as some purely intellectual reveries involving unjustifiable and inconsequential themes and visions (Gunder and Hillier 2009). In many cases, the real effect was that of abandoning reforming aspirations in favour of the adaptive spirit of Postmodernity, that sort of "adaptive realism" of which Koolhaas himself became the exemplary figurehead (Koolhaas 2000). I have dedicated two books to these themes in recent years (Palermo and Ponzini 2010, 2014 forthcoming). What ever is happening to the culture of planning and design in this period, and what can be foreseen for the forthcoming decades? 
Faced with the rising tide of rhetorical communication, it may be useful to seek inspiration in some cases worthy of interest.

\section{Failures and good practice}

The global crisis that has been blighting the world's economy for some time has taken a serious toll on processes of urban transformation. In this scenario, where gaping stretches of emptiness and unfinished projects proliferate, the very fact that an operation reaches its completion may be considered a success. In this way, however, we risk not understanding that at the basis of many failures there lie also endogenous factors, that depend on the culture of the discipline and some concrete stances in terms of institutional and professional practices. The recent experiences of urban development in Milan offer a complete array of possible critical points (I will make brief reference to the destiny of some large projects still under way: Bricocoli and Savoldi 2010; Arcidiacono and Pogliani 2011). The case of Santa Giulia has been a ruinous disaster. This is an area (c. 1,200,000 m2) on the outskirts of the city that, while abandoned, is in a strategic position due to its connection with several important infrastructure networks. In light of this, an ambitious and complex project of spatial development was drawn up, which included a vast park, the placement of innovative tertiary sector businesses and several types of residential complex, one of which was in the luxury category (designed by Norman Foster), and another was a public, but high quality, housing project. To date, only a few fragments of this master plan have become reality, and the forecast is all but good: what is certain is that substantial parts of the approved project cannot be realised; the immediate problem is how to guarantee acceptable temporary solutions to the businesses and inhabitants who are already in situ. The main causes are an underestimation of the problems linked to: environmental pollution - the area featured a number of industrial plants in the past - the bonification costs of which turned out to be far higher than originally thought; the lack of demand, in this phase there is a clear excess in supply in Milan, and this has led to saturation in several segments of the market. Also to be taken into account is the unsustainable competition from other large urban transformation projects being undertaken, such as City Life (to which brief reference will be made shortly), which, in order to survive, attempted to woo several large tertiary firms that were originally ear-marked for the periphery area of S. Giulia. In short, this was a clamorous planning disaster, to which the contribution of urban planning was totally incidental.

The City Life project regards the urban transformation of the old headquarters of the Milan Fair (roughly $400,000 \mathrm{~m} 2$ ), which has by now become inadequate with respect to the new functional requirements. The central nature of the area gave it immense strategic potential. The initial program involved conglomerations rich in tertiary and residential components, to be distributed in a new green park that was to cover about half of the available surface area. The well-known brand of the project consisted of three towers designed by Isozaki, Hadid and Libeskind, each of whom was asked also to plan a specific block of residential units. The project is currently under way, yet has been hampered by several delays and reductions, which in future could become even greater. The limitations were however clear from the beginning. The city of Milan, under the guidance of Mayor Moratti, did not choose the best project among those that participated in the architecture tender, but rather that which guaranteed the greatest financial support, which was in turn necessary for the realisation of the new Urban Fair in the outer area of Rho-Pero. Famous architects designed projects that were generally atopical, i.e. without any relation to the historical, morphological and cultural context (this observation holds true not only for the towers, but also the residential units). The urban park took on a fragmentary and piecemeal character with respect to the placing of the new constructions, and several of its parts risked being inaccessible as they were enclosed within new, high walls. The spatial layout, the distribution and the characteristics of the results of the building activity demonstrated the insufficient nature of the connectivity and porosity of the new enclave with respect to the urban context. Finally, the lack of rail-based transport was seriously underestimated. This should now be compensated for by a new metro line, to be realised with public funding. This case is not such a serious failure as that of S. Giulia, nevertheless, it is difficult to deny that a great strategic opportunity has by and large been lost.

In the meantime, the development project in the Garibaldi-Repubblica area is reaching completion. This is another vast central area (roughly 500,000 m2), with excellent rail and metro links. Also in this case a huge urban park $(150,000 \mathrm{~m} 2)$ is planned; its realisation will constitute the last phase of the project. Today one may observe a dense cluster of towers and new buildings, almost all designed by architects of worldwide renown, which are mostly yet to be used. Amongst the most striking points are: the extremely high settlement density; the dearth of a single ground plan; the atopical character of the single architectural elements, which are thrown together in an almost haphazard fashion; the foreignness of the emerging forms with respect to the urban history and context, the indifference shown towards the direct or unexpected consequences that such large-scale intervention (clearly Gargantuan with respect to the context) wreaks on the entire urban organisation. 
This last point is due to the fact that it creates a strong pole of attraction in the centre of the city and the substantial investment will contribute to the saturation of some segments of the urban, residential and tertiary markets. Therefore, also in this case there are negative consequences to be feared, notwithstanding the fact that there is some indication of success.

How have we reached this point? Certainly the role played by urban planning has been of little importance, both in terms of the capacity to regulate and to orientate. The fundamental choices have regarded the concession of building rights, which are always exaggerated, following a rational of mere building development. The territorial framework is not be considered as a strategic variable; we need go no further than to mention the constant underestimation of infrastructural problems. In most cases, the intervention has been legitimised by way of ad hoc variations of obsolete planning tools. The role of urban design has been essentially decorative, as has the involvement of designers of worldwide renown, which should have guaranteed added value to the building product. In reality, no real attempt whatsoever has been made to examine the links between rules and shapes in greater depth; likewise there has been no attempt to conceive a true spatial framework, to escape from the rationale of the "collage city" (Rowe and Koetter 1978). A lack of capacity to conceive and manage the great urban project as a complex program has been displayed. One which requires guidance and public learning, but also interaction and partnership between the multiple players in the middle time frame, with the possibility for evolutionary developments, which may help to perfect the project in the course of time, without ruining it. Are these limitations specific to the Italian case? The answer is: partly yes. Unfortunately, my country has for some time been governed badly, and not only in this sector. In other nations it is not difficult to identify cases which are of notable interest, that appear to have been able to overcome these difficulties. Several examples come to mind: the port area in Hamburg (the Hafen City project studied by Bricocoli and Savoldi 2013); the Poblenou case in Barcelona; and the transformation of Paris Rive Gauche, the area surrounding the National Library (studied by Davide Ponzini, in Palermo and Ponzini 2014). If we were to conduct an in-depth analysis of these and other similar cases, we would observe not only choices at the antithesis of the mistakes made in Milan, we could also derive interesting considerations with regard to certain more radical nodes, which concern the sense and interpretation of the very disciplines of spatial organisation and transformation.

\section{Bridging the gap between practice and theory}

Why are such cases as the above seen to be relatively successful? The first observation to make is that it is not possible to highlight a sole explicative factor. The results are the emerging effect of a plethora of conditions, requirements and processes, in line with the idea of the "project as an investigation" (Lanzara 1993), i.e. that collective creation that takes shape through networks of social interaction and learning. It is clear that the cultural matrix is pragmatic. This reference framework does not imply however a merely adaptive stance, such as Koolhaas's above-mentioned "realistic" approach. The capacity to innovate is generally linked to the open confrontation between bearers of different intentions, that critically compare and contrast the conditions of the context and the necessity to find a shared synthesis, thanks to the "intelligence of democracy", as Charles Lindblom would put it (Lindblom 1965). Positive results hence hinge upon the interplay between multiple resources and potentialities: public leadership and the possibility to form partnerships with emerging social and economic forces; a policy tools approach as the public sector capacity to choose and combine the most suitable methods of intervention amongst those possible within the specific context; use of the traditional tools of planning and policy making which is proactive, yet ever democratic (i.e. transparent, responsible and legitimate); the capacity to direct practices of urban design in relation to the framework of the territorial layout, to the characteristics of the morphologicalenvironmental context and to the experiences of the life to be hosted in the place; respect for some general requirements for place-making, that in general terms could include features of diversity, resilience, connectivity, and porosity, as well as respect for the human scale of architecture and attention paid to collateral effects. More specific indications clearly depend upon the context (Palermo and Ponzini 2014). These hypotheses are certainly not new - the point is that the theory of planning and that of design do not provide results which are always coherent with this vision inspired by fundamental points of good practice. To the contrary, what it prompts may even be controversial, if not deviant. We will presently consider some salient tendencies.

\section{Crucial issues in urban planning}

The Italian case has for so long presented so many critical points that it risks being of little use as an example in this discussion. We will therefore consider two nations which are traditionally considered to be European planning paradises: the Netherlands and Great Britain. In the former, the 2008 reform had to take into account clear limitations and failures of a planning system based on rigorously rationalistic premises, which involved a complex hierarchy of spatial tools and an accurately predefined interdependence network (Needham 2007). In actual fact it has been necessary to state that plans of 
land use quickly become obsolete, as they generally include norms that are too inflexible and excessively detailed (Buitelaar and Sorel 2010). In practice, forecasts and norms were largely unexpected and hence unable to effectively guide the urban development according to declared aims and programmes (Janssen-Janssen and Woltjer 2010). The large scale plans carried out the main function of verifying conformity to the local choices, but not the proactive role of guide and supporter to the great development process, which would have been necessary in the current phase (ibidem). The solution proposed with the 2008 Planning Act confirmed however, a traditional basis. The land use plan will probably become even more prescriptive. The risk of obsolescence should be countered by the capacity to swiftly formalise alternatives, following the rationale of "continuous planning" (plan-process) that was proposed in Italy by Giovanni Astengo in the 1960's (Astengo 1966). The large scale plans should be re-modelled according to examples of "strategic spatial planning", which apparently took on a critical function in the British planning system in the last ten or fifteen years (Healey 2007). In my opinion each of these hypotheses appears controversial and implausible. The vision of the whole is still substantially traditional. Along this road, there seems to be little hope that innovative, and eventually satisfactory, results may emerge.

The current developments in British planning would appear to display elements confirming this judgement. The two most recent reforms, in 2004 and 2010, within a short period of time, have revealed deep concern and controversial tendencies. Strategic spatial planning tools saw their greatest success with the 2004 reform, as a potential hinge for the vision of economic-territorial development processes supported by Tony Blair's Labour government (Healey 2010). The rationale of the preceding "structure plans" appeared to be too compilatory with aims which were diagnostic and cognitive rather than strategic and projectoriented. Furthermore, it presupposed a main function of public guidance and management of processes, that turned out to be inappropriate in the enactment phase. A more proactive approach was deemed necessary, one which would be both strategic and would involve partnerships, one capable of mobilising and forming networks of a series of social and economic resources. Unfortunately, the difficulties of this endeavour were underestimated, and the planning sector limited itself to proposing edifying ideologies, such as the movement referred to as that of "collaborative planning" (Healey 1997, 2007, 2010). It is hardly surprising that the outcomes of these experiences were disappointing. As a consequence, the new Conservative government led by David Cameron, did away with these presumed cornerstones of the planning system, also with the aim of re-launching the conception of processes of territorial transformation with strong tendencies towards deregulation, which the Thatcher government had proposed in the 1980's. In this way, the problems were not resolved, as standpoint directly merely towards "localism" gives rise to other, well-known problems (Allmendinger and Haughton 2010). However, the inconclusive nature of the strategic approach offered the policy makers valid reasons to enact a counter-reform with respect to the Labour model of governance. Today in the Netherlands do they want to go down the same road?

I have been convinced for some time that several critical points must be faced in a more radical fashion. The objections to the traditional system of land use are obvious, yet the collaborative strand cannot be considered an adequate alternative. It is ill-advised to planner's role to be that of a facilitator in a process: while this which may turn out to be meaningful on the scale of some territorial micro-practices (Susskind and Cruikshank 1987; Forester 1989, 2009), it is less suitable, or more difficult to define with respect to large transformation processes. There is no real reason to believe that planners may play a key role in relation to the interests at hand: not in terms of the presumed cognitive foundation of their proposals, and even less their visionary capacity, i.e. the possibility to take on a substitute role in policy-making. The most plausible results would involve carrying out a methodological and procedural task that, as for every skill that merely concerns management, may be of value only as a complementary resource: if good sustaining ideas and real operative possibilities are amiss, the contribution cannot be anything more than marginal. Finally, crucial regulation dilemmas must not be underestimated. According to the culture of political liberalism, rule of law should be impersonal and decontextualised (Moroni 2007; Alexander et al. 2012). In practice it is difficult to escape the problem of the laws and procedures being used at one's own discretion - the essential point is how to guarantee conditions for the transparency and accountability of the political and administrative system (Booth 2007). The desire to keep the abstract liberal model at a distance derives also from the ever clearer necessity to define location-specific spatial norms: following the principles, which have become relevant again, of form-based normative codes (Soutworth and Ben Joseph 2003; Ben Joseph 2005; Baer 2011), and in general the central nature of a design code in planning practices (Carmona et al. 2003, 2011). Academic reflection on planning, in the Netherlands, in Great Britain, and also elsewhere, has only partly recognised the crucial and interdependent nature of these problems. The point I would like to make is that these considerations represent challenges also to the world of urban design and testify to the indispensable relations between the two fields of experience. 


\section{Dilemmas in urban design}

In actual fact, the literature and experiences of urban design speak of new experiments of considerable interest with respect to certain classic problems: what does doing urban design on a city-wide scale mean? Even more so when faced with the growing variety of current settlement models (informal city, urban sprawl, urban archipelago, megalopolis, megacity (Shane 2011). How may norm systems relating to specific morphological and physical characters of the context be conceived technically (Carmona et al. 2003)? It is to be underlined that these are by no means problems that have not be dealt with before. The criticism aimed at traditional zoning by Giancarlo De Carlo in the 1960's (De Carlo 1964) are no less dense and incisive than the current observations by Ben Joseph (Ben Joseph 2005). The re-launching of the theme of "design code" by Carmona and others in recent years (Carmona et al. 2003, Punter 2010), does not add new elements in terms of analysis and proposal with respect to the elaborations of the "plan idea" by Ludovico Quaroni (Quaroni 1967). These reminders do not aim to be parochial or nostalgic. They merely express disappointment for the fact that certain interesting insights have had little resonance. This is for several reasons, amongst the least of which, the language in which they were delivered. The fact remains that attempts to revise and innovate in this field are not totally unheard of, however, after half a century the results obtained are decidedly underwhelming.

These failures depend on an array of context-based factors, yet we probably must not underestimate the fact that some responsibility lies within the discipline itself. As I have already mentioned (the theme is developed in Palermo and Ponzini 2014), the culture of urban design would seem to be unable to decide between nostalgic longing and arbitrary innovation. I believe it is no longer advisable to cling to traditional models that belong to the days of yore - this is the limitation of numerous experiences of new urbanism and the so-called placemaking strand; on the other hand, one should neither accept the adaptive and sometimes irresponsible spirit of Postmodern culture in an uncritical fashion. The way ahead is composed of critical engagement with respect to the unrealised aspirations of the modern project - as was the case in the 1950's in Harvard, with the mobilisation of great intellectual resources, albeit their being distinctly slow and partial (Krieger and Saunders 2009). My hypothesis is that one of the endogenous limitations of these tendencies is the fragmentation and specialisation of problems. Perhaps it is not enough to seek to perfect norms according to the morphological and environmental nature of the site, if one has underestimated the fact that the resulting differentiation may generate problems in terms of discretion of use. Moreover, it is not enough to perfect rules, if the spatial vision of reference is not specifically based on the real territory, but does no more that proffer general objectives and ideological exhortations about the benefits expected from spatial consideration. Or, if the transformation plan is not deeply rooted in the real context, and does not become one of the cornerstones of the strategic vision for the future. And yet again, if each spatial intervention takes on the characteristics of the local enclave (as in many current place-making operations), without paying sufficient attention to the planned or emerging relations with the territorial framework, which may turn out to be essential to whether it is a success or not.

The self-same projects for green areas or for public services, fundamental nodes in the modern project, are not per se virtuous, if the social and functional context is not auspicious, as was demonstrated some time ago by Jane Jacobs (Jacobs 1961). The conclusion is that virtuous initiatives by the discipline are probably not enough, if meant as solely specialised acts. We should highlight and attempt to re-launch a true "place-based approach" to counter the entirety of these problems (Palermo and Ponzini 2014), going beyond what are purely technical specialisations. Any attempt to integrate the multiple innovations that today seem necessary will raise critical problems, however we are probably left with no alternative. The crucial point is that an appeal to new forms of "integral urbanism" must not remain an ideological exhortation (as occasionally happens: Ellin 1996 and 2011). It must take on a technical and practical form, in a contextualised and coherent fashion, with respect to the interdependent issues of regulation, visioning and planning. Indeed, some successful cases would seem to support this hypothesis (the readers is referred to the examples cited in section 2). Perhaps it is theory that is late.

\section{Challenges for planning and design}

From the discussion put forward herein, it seems to me that we may obtain some useful information. Today the space for problems of urban transformation is a playing field used by the apparatus of several different disciplines and professions, often at the same time, and motivated by interests which are generally competitive. It is not only the case that sole viewpoints do not emerge, to the contrary, the fragmentation appears to be growing, as displayed by the recent references to movements such as new urbanism, placemaking and landscape urbanism. Two instances seem to be of top priority: to distinguish non-equivalent discipline paradigms in each field; and to choose with clarity and a sense of responsibility the stances that seem to answer to some good requirements, in order to create networks and contextually develop the emerging viewpoints, to make the most of their possible synergies. It is useless to do no more that reiterate the old prescriptive conceptions of 
land-use planning. Similarly it is futile to search for opportunities in conceptions of visioning that are merely ideological, or to withdraw into the sphere of formal-technical design, or even worse towards skills that are purely methodological and procedural. It is impossible to avoid comparisons with the independent issues of physical transformation of the territory, in this specific context and phase. This is the illusion that in several crucial phases led the discipline of planning towards paradigms of a rationalistic orientation (Faludi 1973, Boyer 1983). Analogous illusions have appeared within the disciplinary field of policy-making (Howlett and Ramesh 1995; Regonini 2001). This strand is considered by some to be a possible alternative to planning, but the hypothesis does not hold, if what is meant is know-how that concerns only methods and processes. Furthermore, the critical reflection that has developed in the field of policy studies has confirmed the low relevance of the rationalistic approaches to policy analysis the reader is referred to the definitive critiques by Lindblom 1965 and March 1994. In reality, all illuministic conceptions of the connection between knowledge and decisions are undergoing a crisis (Friedman 1987). It would instead appear more fertile to deal with problems by way of "policy inquiry", which adopts a pragmatic orientation, presupposing that the problems and their solutions have their roots in the contexts, and which recognises the interactive and procedural dimension in the decision-making process (Lanzara 1993, Regonini 2001). In this framework, it make be useful to think again on the matter of the choice and combination of the most adequate policy tools, that must not be guided merely by general criteria, but which must take into account the specific nature of the problemin-context (Lascoumes, Le Gales 2004).

It would be equally pointless to see urban design as an auto-referential exercise in design, separate or alternative to planning practices, whether it adopts the simplified canons of new urbanism, or any other ready-made model, from the famous and influential ideal-types of the garden city and the radiant city (Fishman 2011). In reality, urban planning and urban design are practices which are inexorably intertwined. Several critical exponents within the world of planning are aware of this need. Nevertheless, still today they appear to be relatively isolated (Beauregard 1990, Sanyal 2008). Other key scholars have recognised that the problem exists, but do not draw the necessary conclusions. For Gunder, urban design is only a branch of urban planning (Gunder 2011). Patsy Healey admits that place-making is a crucial mission in planning, yet continues to ignore the problems of urban design that should be faced in order to truly realise that viewpoint (Healey 2010). On the other hand, Carmona and others have developed a notion of urban design that is undoubtedly fertile, but which pays little attention to problems related to planning (Carmona et al. 2003; Punter 2010). What legislative and procedural framework, and what planning tools would be most coherent with the idea of urban design that they support? Perhaps these authors simply think that urban design can act as a surrogate to traditional planning.

In reality, it is our opinion that, from the very same practices and from the rare instances of critical thinking, new tendencies emerge, which are probably irreversible, towards new modes of convergence of the traditions of the two disciplines. There is little doubt, in fact, that we must test the potential effects of urban-planning regulation in space and on site, in other words, to perfect form-based normative codes instead of the traditional zoning systems. More in general, we certainly need an adequate "design code", whether it be Quaroni's idea plan, or the more current master plan, to place the territorial transformations in the physical and spatial context. The issue of the urban project is undoubtedly fundamental to the conception and realisation of important urban transformations, however, it should respect a double-barrelled requirement, which is often neglected. On one hand, the emerging projects must be well-rooted within a spatial development framework in order to find coherence and validation (Oosterlynck et al. 2011). Furthermore, it seems indispensable that the programming visions must not be merely indicative, i.e. too abstract or vague. It is not enough to resort to the methodologies of management by objective, which some would like to borrow from the world of corporate planning (where they have also been criticised: see Mintzberg 1994, and Bryson and Einsweiler 1988). Strategic spatial visions should also be more deeply-rooted in these effective places. Perhaps this is the only way to justify their future relaunch, after the clear crisis in recent years, both in institution contexts and in practice. Finally, it is a pleasure to note that some interesting strands of thought have already emerged which wed a policy tools approach with real processes of urban development (Tiesdell and Adams 2011). This is a direction to be developed, as it is potentially coherent with the place-oriented vision described herein.

It is naturally not enough to suggest an ideal vision that is potentially more fertile. We must not forget that we are not talking about new ideas. Precisely in Italy, about half a century ago, extremely important premises and insights were put forward clearly and articulately. Yet the results have been negligible, and at times almost the opposite to that which was hoped for. There are institutional, political, social and cultural conditions that always represent a determining influence. The scholars of the discipline, however, must bear the responsibility for some stances: to recognise that the use of the rules is inevitably to one's own discretion, as are also the indispensable requirements for transparency and accountability; the determining function of the physical and morphological dimensions for regulation and visioning purposes; the central nature of the public inquiry 
and culture of critical pragmatism in the choice and use of policy tools; the sense of the limitations of technical aspects, as the most complex problems to be dealt with involve certain ethical and practical questions (Palermo and Ponzini 2014). If one observes certain concrete experiences that are capable of providing satisfactory results, principals similar to these will seem already clearly pre-empted and tried out. The most common conceptual and rhetorical reference frameworks are probably those areas in which there is the greatest tendency to fumble with the least productive stances, perhaps this is for instrumental reasons. It would appear to be difficult to bridge this gap, with the rigorous critical revision that the cultures of the disciplines should be subjected to. Musings on "uncomfortable knowledge", but also on shining examples of best practice, should offer a robust and convincing impulse to renew the discipline's most traditional approaches and re-design its borders.

\section{Competing interests}

The author declare that he has no competing interests.

Received: 1 November 2013 Accepted: 28 March 2014

Published: 16 May 2014

\section{References}

Alexander ER, Mazza L, Moroni S (2012) Planning without plans? Nomocracy or teleocracy for social-spatial ordering. Progress in Planning 77:37-77

Allmendinger P, Haughton G (2010) The Future of Spatial Planning: Why Less May Be More". Town and Country Planning, July-August, pp 326-328

Arcidiacono A, Pogliani L (2011) Milano al futuro. Riforma o crisi del governo urbano. Edizioni, Milano

Astengo G (1966) "Urbanistica", Enciclopedia Universale dell'Arte, vol. XIV. Sansoni, Venezia

Aymonino C (1975) II significato della città. Laterza, Bari-Roma

Baer WC (2011) Customs, norms, rules, regulations, and standards in design practice"; Carmona M. (2011), "Decoding design guidance". In: Banerjee T, Luokaitou-Sideris A (eds) Urban Design Companion. Routledge, London, pp 277-287

Banerjee T, Luokaitou-Sideris A (eds) (2011) Urban Design Companion. Routledge, London

Beauregard RA (1990) Bringing the city back in". Journal of the American Planning Association 56(2):210-215

Ben Joseph E (2005) The Code of the City. Standards and Hidden Language of Place Making. The MIT Press, Cambridge, MA

Ben Joseph E, Szold T (eds) (2005) Regulating Place: Standards and the Shaping of Urban America. Routledge, London

Birch EL (2011) From CIAM to CNU: the roots and thinkers of modern urban design. In: Banerjee T, Luokaitou-Sideris A (eds) Urban Design Companion Routledge, London

Booth P (2007) The Control of Discretion and the Common Law Tradition. Planning Theory 6:127-145

Boyer C (1983) Dreaming the Rational City. The MIT Press, Cambridge, MA

Bricocoli M, Savoldi P (2010) Milano Downtown. Azione Pubblica e luoghi dell'abitare. Edizioni, Milano

Bricocoli M, Savoldi P (2013) La mixité fonctionnelle à l'épreuve. Une perspective européenne: les expériences de Milan, Copenhaugue, Hamburg. Rapport de recherche, PUCA, Paris

Bryson JM, Einsweiler RC (1988) Strategic Planning: Threats and Opportunities for Planners. Planner Press, Chicago

Buitelaar E, Sorel N (2010) Between the Rule of Law and the Quest for Control: Legal Certainty in the Dutch Planning System". Land Policy 27:983-989

Carmona M (2011) "Design Coding: Mediating the Tyrannies of Practice". In: Tiesdell S, Adams D (eds) Urban Design in the Real Estate Development Process. Wiley-Blackwell, Chichester, pp 288-303

Carmona M, Heath T, Oc T, Tiesdell S (2003) Public Spaces, Urban Spaces. The Dimensions of Urban Design. Architectural Press, Oxford

Cullen G (1961) Townscape. The Architectural Press, London
De Carlo G (1964) Questioni di architettura e di urbanistica. Argalia, Urbino Duany A, Plater-Zyberg E (1991) Towns and Towns-Making Principles. Rizzoli, New York

Dutton JA (2000) New American Urbanism. Reforming the Suburban Metropolis. Skira, Milano

Ellin N (1996) Post-Modern Urbanism. Princeton University Press, New York

Ellin N (2011) Post-modern and Integral Urbanism". In: Banerjee T, LuokaitouSideris A (eds) Urban Design Companion. Routledge, London, pp 589-599

Faludi A (1973) Planning Theory. Pergamon Press, Oxford

Fishman R (2011) "The open and the enclosed: shifting paradigms in modern urban design". In: Banerjee T, Luokaitou-Sideris A (eds) Urban Design Companion. Routledge, London, pp 30-40

Flyvbjerg B (2013) "How planners deal with uncomfortable knowledge: The dubious ethics of the American Planning Association", Cities., 32 June, pp 157-163

Forester J (1989) Planning in the Face of Power. University of California Press, Berkeley

Forester J (2009) Dealing with Differences: Dramas of Mediating Public Disputes Oxford University Press, New York

Friedman J (1987) Planning in the Public Domain. From Knowledge to Action. Princeton University Press, Princeton, NJ

Gunder M (2011) Commentary: is urban design still urban planning? An exploration and response. Journal of Planning Education and Research 31(2):184-195

Gunder M, Hillier J (2009) Planning in Ten Words or Less. A Lacanian Entanglement with Spatial Planning. Ashgate, Surrey, UK

Healey P (1997) Collaborative Planning: Shaping Places in Fragmented Societies. Macmillan, London

Healey P (2007) Urban Complexities and Spatial Strategies. Towards Relational Planning for Our Time. Routledge, London

Healey P (2010) Making Better Places. The Planning Project in the Twenty-First Century. Palgrave Macmillan, London

Howlett M, Ramesh M (1995) Studying Public Policy. Oxford University Press, Toronto

Huet B (1984) The city as a dwelling space. Alternatives to the charter of Athens, Lotus 41:6-17

Jacobs J (1961) The Death and Life of Great American Cities. Random House, New York Janssen-Janssen LB, Woltjer J (2010) British Discretion in Dutch Planning: Establishing a Comparative Perspective for Regional Planning and Local development in the Netherlands and the United Kingdom". Land Policy 27:906-916

Katz P (1994) The New Urbanism: Toward an Architecture of Community McGraw-Hill, New York

Koolhaas R (2000) "Junkspace" In: Yoshida N (ed). OMA@work, A+U Publishing, Tokyio, pp 408-421

Koolhaas R (1995) "What ever happened to urbanism", In: Koolhaas R, Mau B (eds). S, M, L, XL, Taschen, Köln, pp. 961-971

Krieger A, Saunders WS (eds) (2009) Urban Design. University of Minnesota Press, Minneapolis

Lanzara GB (1993) Capacità negativa. Competenza progettuale e modelli di intervento nelle organizzazioni. il Mulino, Bologna

Lascoumes P, Le Galès P (eds) (2004) Gouverner par les instruments. Presses de Sciences Po, Paris

Lindblom CE (1965) The Intelligence of Democracy. The Free Press, New York

Maciocco V (ed) (2008) Urban Landscape Perspectives. Springer Verlag, Dordrecht, Heidelberg, London, NewYork

Madden K (2011) Place-making in Urban Design. In: Banerjee T, Luokaitou-Sideris A (eds) Urban Design Companion. Routledge, London, pp 654-662

March JG (1994) A Primer on Decision Making: How Decisions Happen. The Free Press, New York

Mintzberg H (1994) "The Rise and Fall of Strategic Planning. Reconceiving Roles for Planning, Plans, Planners". Harvard Business Review, Cambridge, MA, pp 107-114, January-February

Moroni S (2007) Planning, liberty and the rule of law. Planning Theory 6(2):107-111

Mostafavi M, Najle C (eds) (2003) Landscape Urbanism. A Manual of the Machinic Landscape. Architectural Associaton Press, London

Mumford E (2009) The Emergence of Urban Design in the Breakup of CIAM. In: Krieger A, Saunders WS (eds) Urban Design. University of Minnesota Press, Minneapolis, pp 15-37

Needham B (2007) Dutch Land Use Planning; Planning and Managing Land-use in the Netherlands. Sdu Uitgevers, Den Haag

Oosterlynck S, van den Broeck J, Albrechts L, Moulaert F, Verhetsel A (eds) (2011) Strategic Spatial Projects. Catalysts for Change. Routledge, London

Palermo PC, Ponzini D (2010) Spatial Planning and Urban Development: Critical Perspectives. Springer Verlag, Dordrecht, Heidelberg, London, NewYork 
Palermo PC, Ponzini D (2014) Place-Making and Urban Development. Challenges for Contemporary Planning and Design. Routledge, London, forthcoming Panerai P, Depaule J, Demorgon M (1999) Analyse urbaine. Parenthèses, Marseille Ponzini D, Nastasi M (2011) Starchitecture: Scenes, Actors and Spectacles in Contemporary Cities. Allemandi, Torino

Portas N (1998) "L'emergenza del progetto urbano". Urbanistica 110:51-60 Project for Public Spaces (PPS) (2008) Metropolitan Planning Council (MPC). A Guide to Neighborhood Placemaking in Chicago. PPS/MPC, Chicago

Punter J (ed) (2010) Urban Design and the British Urban Renaissance. Routledge, London

Quaroni L (1967) La Torre di Babele. Marsilio, Padova

Regonini G (2001) Capire le politiche pubbliche. il Mulino, Bologna

Rowe C, Koetter F (1978) Collage City. The MIT Press, Cambridge MA

Sanyal B (2008) "Critical about Criticality" Critical Planning. UCLA Journal of Urban Planning, Summer 2008:142-160

Shane DG (2011) Urban Design since 1945: A Global Perspective. Wiley, Chichester Sitte C (1889) Der Städte Bau nach seinen Künstlerischen Gründsätzen. Graeser Verlag, Wien

Soja EW (2000) Post-metropolis: Critical Studies of Cities and Regions. Blackwell, Oxford

Soutworth M, Ben Joseph E (2003) Streets and the Shaping of Towns and Cities. Island Press, Washington

Susskind L, Cruikshank J (1987) Breaking the Impasse. Consensual Approaches to Resolving Public Disputes. Basic Books, NewYork

Tiesdell S, Adams D (2011) Urban Design in the Real Estate Development. Blackwell, London

Unwin R (1909) Town Planning in Practice: An introduction to the Art od Designing Cities and Suburbs. Fischer Unwin, London

Waldheim C (ed) (2006) Landscape Urbanism: A Reader. Princeton Architectural press, Princeton, NJ

doi:10.1186/2195-2701-1-7

Cite this article as: Palermo: What ever is happening to urban planning and urban design? Musings on the current gap between theory and practice. City, Territory and Architecture 2014 1:7.

\section{Submit your manuscript to a SpringerOpen ${ }^{\circ}$ journal and benefit from:}

- Convenient online submission

- Rigorous peer review

- Immediate publication on acceptance

- Open access: articles freely available online

- High visibility within the field

- Retaining the copyright to your article

Submit your next manuscript at $\gg$ springeropen.com 